\title{
Practices in Handling Clinical Samples in a COVID-19 Laboratory - An Experience from Chennai, India
}

\author{
Saramma Mini Jacob루, Kanagasabai Sivasangeetha², Durairaj Anitha ${ }^{3}$, Singaram Kaplana ${ }^{4}$ \\ 1, 2, 3, 4 Department of Experimental Medicine, The Tamilnadu Dr. MGR Medical University, \\ Chennai, Tamilnadu, India.
}

In early January 2020, China had started raising concerns of a new contagious disease caused by new strains of coronavirus, Severe Acute Respiratory SyndromeCoronavirus-2 (SARS-CoV-2). The World Health Organization (WHO) on March 11, 2020, had declared the novel coronavirus (COVID-19) outbreak a global pandemic. COVID-19 was transmitted from person to person through respiratory droplets generated when an infected person coughs, sneezes, breathing or through contact with a surface that has been contaminated ${ }^{1}$ and through aerosols-airborne microdroplets. ${ }^{2}$ The clinical manifestations of COVID-19 represents a wide spectrum of disease ranging from mild to severe respiratory syndrome influenza-like illness with mainly lower respiratory tract symptoms, complicated by pneumonia and Acute Respiratory Distress Syndrome (ARDS), high fever, and headache. In many cases, loss of taste and smell and severe gastrointestinal symptoms were reported, as are cardiac problems, with the latter being perhaps secondary to a cytokine storm such as is seen in the more severely affected patients. ${ }^{3}$ WHO COVID-19 dashboard on June $25^{\text {th }} 2021$ showed $179,686,071$ confirmed cases worldwide. ${ }^{4}$

COVID-19 started unfolding in India in end of January 2020 and the Government of India declared nation-wide lockdown by March $24^{\text {th }} 2020$. As per WHO dashboard, there were $30,144,445$ confirmed COVID-19 cases in India as on June $25^{\text {th }} 2021.4$ The first case of confirmed COVID-19 infection in India was reported from Kerala. This was a female student who had returned to Kerala from Wuhan, China because of the COVID-19 outbreak situation there. ${ }^{5}$ The clinical samples had to be transported to National Institute of Virology (NIV), Pune for confirmatory testing. At that time, NIV was the only laboratory for testing SARS-CoV-2. Gradually, as the cases increased, testing was scaled up throughout the country and Reverse Transcription-Polymerase Chain Reaction (RT-PCR) testing facility was made available in almost all government medical colleges, research institutes and private facilities. At present, testing can be done in an Indian Council for Medical Research (ICMR) approved laboratory. As per ICMR, total samples tested as on June $27^{\text {th }} 2021$ were 40, 63, 71, 279. 6 Therefore, laboratory testing is a pillar of the COVID-19 outbreak response. 7 This article presents the practices in handling clinical specimens in a COVID-19 laboratory in relation to manpower, machine/equipments and material/consumables.
Corresponding Author: Dr. Saramma Mini Jacob, Department of Experimental Medicine, The Tamilnadu Dr. MGR Medical University, No. 36, Anna Salai, Guindy, Chennai-600032, Tamilnadu, India E-mail:saramini@yahoo.com

DOI: $10.14260 /$ jemds/2021/711

How to Cite This Article:

Jacob SM, Sivasangeetha K, Anitha D, et al. Practices in handling clinical samples in a COVID-19 laboratory - an experience from Chennai, India. J Evolution Med Dent Sci 2021;10(39):3508-3510, $10.14260 /$ jemds/2021/711

Submission 19-07-2021,

Peer Review 12-09-2021, Acceptance 18-09-2021, Published 27-09-2021.

Copyright (c) 2021 Saramma Mini Jacob et al. This is an open access article distributed under Creative Commons Attribution License [Attribution 4.0 International (CC BY 4.0)] 


\section{Manpower}

The medical personnel engaged in testing are the front-line workers. Their safety is primary concern in laboratory procedures. Many of the laboratory staff were scared to work in the COVID-19 laboratory. They had to be motivated, encouraged and assured that all preventive measures were taken for their safety. As the first safety precaution, they were provided training on donning and doffing of the personal protective equipment (PPE) including coveralls, double gloves, N95 respirator mask, goggles, head cover, leg and shoe cover. Clinical samples were received in the laboratory every day from May $5^{\text {th }} 2020$. The Chennai corporation had divided the district into 15 zones and we received samples from one zone in the city. These samples along with the patient requisition forms were transported to the laboratory in vaccine carriers and handed over to the technicians who are available in the reception area. Timely communication is important between the community health care workers and laboratory personnel for effective coordination and implementation. The laboratory technician with PPE receives the samples and they are placed onto tube racks inside a biosafety cabinet. All the samples were provided laboratory identification number (Lab ID) and tested. The lab ID's were entered manually in the requisition forms and they were kept in the reception area. For soft copy, a computer and printer were dedicated for entry of sample and lab ID nos.

The junior laboratory staff were trained in the molecular extraction method. Initially, manual extraction was performed for only 30 samples per day. At present, they were able to perform manual extraction of 400 - 450 samples per day with a turnaround time of 24 hours. Six laboratory staff did 7 days of 12 hours duty and then given off for the next 7 days (quarantined). This was not without challenges. The column transfer in the manual extraction method was tedious and took long hours to complete the test resulting in strain and back pain. The frequent opening and closing of the tubes in each step was laborious and some of the staff developed calluses at the fingertips.

The main challenge faced was to keep the staff safe from getting infected without disturbing their productivity. The authorities of the University took care of their transportation, boarding and lodging during the lockdown days. The head of the laboratory and other administrative staff needed to be caring, communicative and had to support them with flexibility of their working schedule.

\section{Machines (Equipments)}

The existing molecular laboratory in the department was transformed into a COVID-19 laboratory and the clinical samples were handled and processed in a Class II biosafety cabinet (BSC). The PCR extraction room had an attached smaller room where donning and doffing was done by the laboratory personnel. The donning and doffing procedures and standard operating procedure (SOP) were displayed in that room. The samples with lab ID numbers were processed in the PCR extraction room. Since the extraction method was performed manually, there were chances of surface contamination, aerosol generation with centrifugation and fomite formation as a result of pipetting.

Surface disinfection was done using $70 \%$ ethanol or $1 \%$ sodium hypochlorite solution. All surfaces and equipments including the biosafety cabinets, refrigerated centrifuge, pipettes, vortex mixer, fridge and -20 deep freezer and other surfaces were wiped with disinfectants before and after the close of work. Every day, before and after performing the test, the biosafety cabinets were exposed to ultra violet (UV) light. There was a window air conditioner in the PCR extraction room and its filters were cleaned every month.

The main challenge with the machines/equipments (e.g. refrigerated centrifuge) was the breakdown due to continuous usage. For any breakdown, the service engineers were called for repair. Manual extraction method warrants daily cleaning of the refrigerated centrifuge and pipettes.

\section{Materials (Consumables)}

All procedures were performed in a way to minimize aerosols and prevent infection. The clinical samples received were two swabs (nasopharyngeal and oropharyngeal specimens) in a screw capped $15 \mathrm{ml}$ polypropylene clear conical centrifuge tube containing viral transport media. The challenge while receiving the sample was the leakage of clinical material due to improper closure of the screw cap. With regard to other consumables, initially there was shortage of N95 masks and PPE. So, indent had to be provided well in advance to procure materials in bulk. This also includes the supply of microlitre tips, $2 \mathrm{ml}$ tubes, storage vials and other basic consumables needed for the laboratory work. The decontamination of the surfaces of the workspace and equipments with freshly prepared $1 \%$ sodium hypochlorite solution and $70 \%$ ethanol respectively might have prevented the surface contamination. At the start, hand sanitizers were out of stock and were very expensive. Therefore, the higher authorities of the University encouraged the department to make the hand sanitizer in the department as per the WHO formulation. They were installed in the entry area and also in all the laboratory areas. The staff were encouraged to wash hands with soap and water/hand sanitizer frequently. Colour coded bins were used for segregation of waste as per the local biomedical waste management (BWM) guidelines. For proper disposal of biomedical waste, small, medium and large non-chlorinated yellow coloured plastic bags had to be purchased so that the waste is disposed in the proper manner. Every weekend, RNA extraction and sample labelling rooms were fumigated with formaldehyde and potassium permanganate.

The main challenges with regard to materials used for laboratory work were ensuring adequate supplies and inventory of consumables in order to run the laboratory without a hitch.

With the current scenario of COVID-19 pandemic, it is inevitable that the testing laboratories take measures and plans to ensure the safety of the laboratory personnel along with providing quality testing services. Thus far, the laboratory has tested more than 100,000 samples. Sharing our experience and challenges will benefit other laboratory professionals in adopting better safety measures and testing services.

Financial or other competing interests: The authors acknowledge the financial support provided by the Tamil Nadu Dr MGR Medical University.

Disclosure forms provided by the authors are available with the full text of this article at jemds.com. 


\section{REFERENCES}

[1] Zhang R, Li Y, Zhang AL, et al. Identifying airborne transmission as the dominant route for the spread of COVID-19. Proc Natl Acad Sci 2020;117(26):14857-63.

[2] Borak J. Airborne transmission of COVID-19. Occup Med (Lond) 2020;70(5):297-9.

[3] Triggle CR, Bansal. D, Farag EABA, et al. COVID-19: learning from lessons to guide treatment and prevention interventions. mSphere 2020;5(3):e00317-20.
[4] WHO Coronavirus Disease (COVID-19) Dashboard. https://covid19.who.int/ [cited 28 June 2021]

[5] Andrews MA, Areekal B, Rajesh KR, et al. First confirmed case of COVID-19 infection in India: a case report. Indian J Med Res 2020;151(5):490-2.

[6] SARS-CoV-2 (COVID-19) Testing Status. https://www.icmr.gov.in/ [cited 28 June 2021]

[7] Ondoa P, Kebede Y, Loembe MM, et al. COVID-19 testing in Africa: lessons learnt. Lancet Microbe 2020;1(3):e1034. 